\title{
Por uma "consciência sanitária" revolucionária: a participação do médico Belisário Penna em outubro de 1930
}

\author{
Leonardo Dallacqua de Carvalho*
}

\section{RESUMO}

Analiso a participação do médico Belisário Penna no golpe de Estado de 1930. Investigo a trajetória de Penna como médico e homem público nos anos finais da década de 1920. Discuto sua aproximação com Getúlio Vargas, a repercussão da tomada de poder em impressos periódicos, as correspondências recebidas e de que modo ocorreu a sua entrada no cargo de diretor do Departamento Nacional de Saúde Pública, no Governo Provisório. Em particular, apresento um sanitarista que propunha por meio de uma "consciência sanitária" um Brasil integrado regionalmente, centralizado politicamente e administrativamente e capaz de viabilizar uma reforma nacional na saúde pública.

Palavras-chave: Revolução de 1930; Belisário Penna; saúde pública.

\section{For a revolutionary "Health Consciousness": the participation of doctor Belisário Penna in October 1930}

\begin{abstract}
This article discusses doctor Belisário Penna's role in Brazil's 1930 coup, focusing on his actions as a physician and public figure in the late 1920s. It explores Penna's connection with president Getúlio Vargas, the repercussions of the coup in the press, letters he received from different sources, and how he became director of the Brazilian National Department of Public Health during the Provisional Government (1930-1934). In particular, the article looks at Penna as a public health official who proposed using "health consciousness" to create a Brazil that was regionally integrated, politically and administratively centralized, and capable of carrying out national public health reform.
\end{abstract}

Keywords: Revolution of 1930; Belisário Penna; public health.

DOI: http://dx.doi.org/10.1590/2237-101X02204814

Artigo recebido em 22 de julho de 2020 e aceito para publicaçáo em 24 de novembro de 2020.

* Professor da Universidade Estadual do Maranhão / Programa de Pós-Graduação em História (PPGHIST), São Luís/MA - Brasil. Bolsista de Desenvolvimento Científico Regional CNPq C. E-mail: leo.historiafiocruz@gmail.com. ORCID: https://orcid.org/0000-0002-7893-3092. 


\section{Por una "consciencia sanitaria" revolucionaria: La participación del médico Belisário Penna en octubre de 1930}

\section{RESUMEN}

Analizo la participación del médico Belisário Penna en el golpe de Estado de 1930. Investigo la trayectoria de Penna como médico y hombre público en los años finales de la década de 1920. Discuto su aproximación con Getúlio Vargas, la repercusión de la tomada del poder en periódicos impresos, las correspondencias recibidas y de qué modo ocurrió su entrada en el cargo de director del Departamento Nacional de Salud Pública, en el gobierno provisional. En particular, presento un sanitarista que proponía por medio de una "consciencia sanitaria" un Brasil integrado regionalmente, centralizado políticamente y administrativamente, y capaz de viabilizar una reforma nacional en la salud pública.

Palabras Clave: Revolución de 1930; Belisário Penna; salud pública.

\section{Introdução}

O significado político de outubro de 1930 pode ser definido antes mesmo do fato per si, ainda no início das suas confabulaçôes. Há diversos caminhos, em perspectiva histórica, para compreender o seu controverso desdobramento. A derrota de Getúlio Vargas (1882-1954) nas urnas para o advogado Júlio Prestes (1862-1946) iniciou um movimento que impediu o jurista paulista de tomar posse. Na década de 1920, parte das demandas morais e de mobilização presentes nesse evento estava alinhada às aspiraçóes do movimento tenentista. Oficiais inspirados em autores como Alberto Torres (1865-1917) exigiam uma ação revolucionária que transformasse o governo em um regime forte cujo Estado centralizador seria o agente reformador do país. A rigor, diferentes narrativas contracenavam para legitimar ou contestar o episódio armado de 1930. Após a tomada de poder pelo grupo aliancista, impressos periódicos, como trataremos adiante, disputavam em suas linhas editoriais o sentido daquela mobilização armada. Afinal, era uma "Revolução Vitoriosa" ou um "Golpe de Estado"?

A historiografia não se furtou periodicamente em buscar nas interpretações conceituais e contextuais uma definiçãao mais precisa do período iniciado pelo grupo de Vargas. Isto é, versar a respeito deste tema é considerar a participação de grupos e forças políticas bastante diversificadas e como "[...] distintas eram as visóes a respeito da condução do processo revolucionário" (PANDOLFI, 1999, p. 9). Se o ponto de partida investigado for apenas a identificação das rupturas entre a Primeira República e o Governo Vargas, o insucesso será o único resultado. São nas forças que disputavam centralizaçóes e projetos autoritários ou nas que pleiteavam um novo projeto liberal com mais autonomia regional é que se observa um regime que nasce repleto, também, de continuidades. Em termos políticos e de saúde 
pública, cito como exemplo no plano das continuidades as obras de Cláudia Viscardi, $O$ teatro das oligarquias (2019), Cristina Maria Oliveira Fonseca, Saúde no Governo Vargas (1930-1945) (2007) e o capítulo de Elisa Reis, "Poder privado e construção do Estado sob a Primeira República" (1991), como essenciais para perceber as rupturas e permanências em volta dos projetos de nação das décadas de 1920-1930. Assim sendo, como esclarece Gilberto Hochman, o campo da saúde pública foi expandido consideravelmente na década de 1920, permitindo a Vargas, posteriormente, "[...] uma estrutura administrativa com um poder ampliado de intervenção sobre a saúde pública que não sofreu alteraçóes significativas justo num momento em que a centralização e a expansão do Estado se davam de maneira inédita na história brasileira" (HOCHMAN, 1993, p. 40).

Um ponto chamativo versado pela historiografia no que se refere à dificuldade em tratar o movimento de 1930 deve-se à memória afetiva cultivada em personagens como Vargas. Basta observar dentro do próprio espectro de 1930 a 1945 as perspectivas plurais que podem ser realizadas da ação de Vargas durante os diferentes projetos de poder que propôs no curso de uma década e meia. A memória de Vargas conserva muitas vezes uma interpretação maniqueísta que interage com momentos da sua trajetória, como no caso do Golpe de 1930. Noé Sandes (2009), nesse sentido, avalia o peso dos memorialistas para a formação de uma consciência histórica de outubro de 1930 e de que modo as interpretaçóes dos revolucionários vitoriosos percorreram os escritos historiográficos.

Haja vista a dificuldade consensual, não significa que a discussão foi estagnada. A análise não se limita mais, como no passado da historiografia relatado por Aspácia Camargo (1980, p. 11), em opinióes que se dividiam entre aquelas cuja interpretaçáo do fenômeno de 1930 constituía uma resposta de um profundo interesse de uma classe média emergente versus os que percebiam um movimento de instauração da dominação burguesa.

O debate tem rendido, visto que 90 anos depois a historiografia permanece refletindo os caminhos que levaram diferentes personagens a apoiar o movimento. São atores históricos que ora concordam e permanecem na estrutura montada por Vargas, ora se decepcionam e se afastam frente aos resultados da sua gestão. A participação de Belisário Penna (18681939), portanto, sugere parte de várias dessas sensaçôes às quais me refiro. O médico barbacenense experiencia desde a mobilização e empolgação à frustração com o novo regime.

Por certo, o argumento que melhor define o meu ponto inicial está alinhado à Pandolfi e Grynszpan (2003, p. 8) quando abordam a concepçâo de outubro de 1930:

Supor, entretanto, que a implantação de tal projeto se deu naturalmente, isto é, sem conflitos, é negar a complexidade de um processo regido pela ambição que tinham os diversos segmentos da sociedade de assegurar para si o controle da nova máquina de Estado que se montava.

A partir do fragmento acima e considerando as disputas de poder entre os diferentes grupos envolvidos é admitido tratar a "Revolução de 1930" como um "golpe de Estado 
de 1930". A perspectiva histórica permite acompanhar a continuidade do movimento para concordar que distintos segmentos da sociedade ambicionavam o controle da máquina do Estado. Os projetos de nação pensados no centralismo político e no autoritarismo - mas não somente neste eixo, como também por meio de um novo projeto liberal - acabaram encontrando maior espaço na nova configuração política.

Há diferentes abordagens historiográficas sobre o caráter revolucionário do movimento (OLIVEIRA, 1978; FERREIRA; PINTO, 2008). Uma das mais marcantes é a de Virgínio Marques Santa Rosa (1976), na qual elege como decisiva a participação transformadora das classes médias. Tal concepção expressa o aparecimento dessas classes devido aos conflitos entre uma burguesia nacional e outra média-urbana, sobretudo em decorrência do processo eleitoral de 1930. Tese que, como vimos, foi questionada por autoras como Aspácia Camargo.

Outra perspectiva em destaque avalia o outubro de 1930 como uma revoluçáo ao considerar a possibilidade de uma reorganização estrutural com a decadência da oligarquia política dominante. É, como expóe Boris Fausto (1990, p. 246), “[...] uma aliança temporária entre as facçóes burguesas não vinculadas ao café, as classes médias e o setor militar tenentista”. Há um conjunto de manifestaçôes de caráter moral, político e demais interesses que borda a uniáo. A conspiraçáo alterou a relaçáo no seio da classe dominante privilegiando setores para além do agroexportador e, inclusive, criou uma expressão política heterodoxa e uma nova dinâmica com a classe operária (FAUSTO, 1990, p. 247). Nesse caso, em termos políticos, o Estado de compromisso foi o ponto de reconfiguração do vazio de poder deixado após a derrubada da burguesia cafeeira (FAUSTO, 1997, p. 150). Ao excluir os mitos dualistas, Fausto também contestou a redução do movimento tenentista como ação política das classes médias, uma intepretação presente em Santa Rosa. Portanto, o movimento é tratado como revolução mesmo que não haja "[...] alteração das relaçóes de produção na instância econômica, nem na substituição imediata de uma classe ou fração de classe na instância política" (FAUSTO, 1997, p. 116).

O argumento de Luciano Martins, ao analisar se de fato a Revoluçáo de 1930 deve ser tratada como um marco cronológico, menciona a ambiguidade da expressão que, nesse sentido, pode designar tanto o processo que indicou rupturas em parte do sistema político, quanto o episódio político específico (MARTINS, 1980, p. 672). Pensando a reestruturação de uma elite enquanto dirigente, mas não como classe dominante, pondera:

Mas tal mudança não significou nem o "golpe da burguesia", como a Revolução de 30 chegou a ser caracterizada (ou caricaturada) por um autor [Werneck Sodré], nem a implementação dos "ideais democráticos" inscritos no discurso dos revolucionários de 30, nem muito menos o fim da dominação oligárquica no campo (MARTINS, 1980, p. 680). 
Da perspectiva de Lucia Lippi Oliveira, mesmo com o debate percorrendo os anos 1980 no que diz respeito ao movimento ser ou não revolucionário, há o consenso daquele momento ter: "[...] representado a procura de um novo equilíbrio das classes dominantes regionais em consequência da quebra da coesão das antigas oligarquias e do remanejamento dos quadros políticos da Primeira República” (OLIVEIRA, 1978, p. 112). Outra obra, Regionalismo e centralizaçâa política (1980), por exemplo, expressa a relaçáo entre as classes dominantes, os estados e formação do governo varguista. Tendo em vista um tema que se estende por 90 anos - e que aparentemente está longe de ser esgotado -, esta breve reflexáo de uma fração da bibliografia amplia as possibilidades de abordagens conceituais.

Outro prisma importante se refere à saúde pública. A relação entre saúde pública e política diz respeito, entre outras, à coletivização da saúde como um bem público integrado a um projeto nacional cujo Estado é seu agente realizador (HOCHMAN, 1993, p. 42). Penna defendeu com fervor essa perspectiva por meio da sua produção intelectual e mobilização política/intelectual - mediante a criação da Liga Pró-Saneamento do Brasil (1918). Em síntese, o conceito de interdependência desenvolvido por Hochman sugere a necessidade desses atores históricos em rediscutir a Constituição de 1891 em termos de saúde pública. Embora a Constituição garantisse a autonomia para os estados, os efeitos negativos de uma epidemia ou doenças tropicais, por exemplo, mobilizaram setores intelectuais e políticos na busca por soluçôes. A "consciência sanitária", desse modo, nasce no discurso de Penna como uma alternativa às consequências da descentralização da Constituição de 1891.

O objetivo deste artigo é demonstrar o processo de participação do médico Belisário Penna no curso dos acontecimentos de outubro de 1930. Com efeito, Penna se torna mais uma chave explicativa, em termos de pluralidades dos atores históricos que participaram do movimento, para compreender quais projetos de nação concorriam no final da década de 1920. Mais ainda, como a sua pauta estruturada na "consciência sanitária" encontrava fôlego a partir do envolvimento com a tomada de poder. Poucas semanas após o sucesso da açáo armada, Penna ocupou o cargo de Diretor do Departamento Nacional de Saúde Pública (DNSP) e, no ano seguinte, esteve interinamente, por três meses, como Ministro do Ministério de Educação e Saúde Pública (MESP).

\section{A escalada político-administrativa de Belisário Penna}

Belisário Augusto de Oliveira Penna nasceu em 1868 na cidade de Barbacena, no Estado de Minas Gerais. Filho do Visconde de Carandaí, completou seus estudos secundários no Colégio Abílio, fundado e dirigido pelo reconhecido educador brasileiro Abílio César Borges (1824-1891), o Baráo de Macaúbas. Posteriormente, cursou medicina na Faculdade de Medicina do Rio de Janeiro, mas transferiu-se para a faculdade de Medicina da Bahia, na 
qual obteve o diploma em 1890, aos 22 anos. Atuou como clínico em diferentes cidades de Minas Gerais. Na cidade de Juiz de Fora, na ocasiáo, foi comerciante e ocupou o cargo de vereador no início do novo século. Em 1904 se deslocou à capital federal após ser aprovado em concurso referente à nomeação de Inspetor Sanitário da Diretoria Geral de Saúde Pública, vinculado a Oswaldo Cruz (1872-1917), com as funçôes posteriormente designadas na 4a Delegacia de Saúde.

Embora presente desde 1904 como Inspetor Sanitário no quadro profissional do Instituto de Manguinhos, sua apariçáo na cena pública tem origem em meados da década de 1910. Nesse período, as expediçóes científicas de Manguinhos traduziam o momento modernizante do país e o seu estágio de ciências. Ao passo que eram expandidas as fronteiras do Rio de Janeiro e de outras grandes cidades, por meio de projeto de infraestrutura, maior ligação e escoamento econômico, as doenças atravancavam o "sentimento de progressão". As pesquisas na área da entomologia credenciavam o Instituto de Manguinhos como autoridade para debelar as doenças. Para a historiadora Simone Kropf (2009, p. 76), as expediçôes forneciam subsídios para os estudos das condiçóes sanitárias em diferentes regióes e ajudavam a conter as crises epidêmicas que prejudicavam a expansão estrutural das obras públicas e privadas.

Acompanhado de nomes da ciência nacional como Oswaldo Cruz, Carlos Chagas (1879-1934) e Artur Neiva (1880-1943), Belisário Penna fez parte de diversas expediçóes científicas. Viajando independente ou sob a chancela de Manguinhos, visitou todas as regióes do país, permitindo-lhe uma visão geral do quadro sanitário brasileiro. Sua atuação como médico nas expedições possibilitou uma interpretação das necessidades urgentes das populaçóes interioranas tendo em vista o seu estado de abandono pelo poder público. Como menciona Nísia Trindade Lima (1999), essa leitura de país transformou médicos como Penna em "sociólogos por acaso" ao defrontar com situaçóes em que o analfabetismo, o alcoolismo e as doenças eram dominantes entre a população brasileira para além dos grandes centros urbanos.

Assim surgia um projeto nacional-reformista pela via da saúde pública, mais precisamente pelo que nomeou de "consciência sanitária". Em síntese, se o poder público adotasse uma política centralizadora de saúde pública, pensando coletivamente, haveria a possibilidade de unificação e o despertar de um "sentimento de nacionalidade". Para Penna, o resultado dessa ação engendraria uma "raça brasileira" homogênea e totalmente integrada aos países ditos civilizados. Tal bandeira foi alçada a partir da publicação de artigos em impressos periódicos como Correio da Manhã e do enfeixamento desses textos no livro Saneamento do Brasil, publicado em 1918. A essa altura, com 50 anos de idade, Penna almejava a criação de uma Liga Pró-Saneamento, cujo caráter nacionalista enviesado para a saúde pública seria a porta de entrada do Brasil para a civilização. Tais discussóes foram devidamente exploradas em Castro-Santos (1985), Reis (1991), Hochman (2012), Lima (1999), Carvalho (2019) e Lippi 
Oliveira (1990). À medida que Penna avançava com seu projeto reformista, automaticamente era absorvido nos quadros burocráticos do Estado.

Foi por essa razáo que compôs a burocracia de todos os governos presidenciáveis após a divulgação do seu projeto nacional-reformista. À exceção do governo Artur Bernardes (1922-1926), de quem divergiu e chegou a ser preso, Penna participou da linha do tempo de presidenciáveis que segue de Wenceslau Brás a Getúlio Vargas. Sua presença sempre esteve relacionada aos quadros institucionais da saúde pública.

Após a ascensão de Washington Luís à presidência da República (1926-1930), Penna foi convidado, em 1928, a ocupar o cargo de Inspetor de Propaganda e Educação Sanitária. Não era a primeira vez que firmava parcerias com o atual presidente. Anos antes, quando Washington Luís era presidente do Estado de São Paulo (1920-1924), Penna foi solicitado para desenvolver materiais educativos relacionados às doenças para escolas normais e escolas primárias do estado.

Embora suas funções estivessem alocadas na esfera federal, Penna foi requisitado pelo presidente do Estado do Rio Grande do Sul, Getúlio Vargas (1928-1930), para elaborar estatísticas, examinar as condiçóes sanitárias e realizar palestras e conferência no Rio Grande do Sul. Além de textos e estudos sobre a lepra, doença à qual vinha se dedicando nos últimos anos, publicou o folheto Passado, presente e futuro do Rio Grande do Sul. Assim sendo, a ida ao estado possibilitou uma aproximação política com Vargas, que àquela altura recusava a ala tradicional liberal gaúcha e ascendia com um discurso de renovaçáo da política rio-grandense. A despeito de considerar Washington Luís um aliado, Penna se afastaria cada vez mais do presidente da República à medida que se aproximava de Getúlio Vargas.

\section{"Consciência sanitária" e participação no movimento de 1930}

A "consciência sanitária" foi um conceito formulado por Penna de caráter nacional-reformista. Por meio da sua formação técnico-científica, o sanitarista brasileiro realizava uma leitura de país que exigia uma tomada de consciência das classes dirigentes em relação à saúde pública. Era uma crítica não somente ao comportamento dos homens públicos, mas ao sistema federalista advindo da Constituição de 1891, que elegia prejudicial para a ajuda mútua entre os estados e a União. A ocupação de cargos na Primeira República por homens poderosos da elite brasileira, em conluio para a manutenção e perpetuação do poder, foi uma característica nesse período. O federalismo encorpou essa máxima a partir das articulaçóes entre coronéis locais com governos estaduais e federais. Em tempo, como nos lembra Victor Nunes Leal, o coronelismo era "[...] um compromisso, uma troca de proveitos entre o poder público, progressivamente fortalecido, e a decadente influência social dos chefes locais, notadamente dos senhores de terras" (LEAL, 1975, p. 20). 
De modo geral, sua percepção estava ligada à falência moral da República na qual considerava que a situação social, política, econômica e moral brasileira era fruto do pacto federalista e dos acordos firmados entre homens que buscavam seus próprios interesses. Precisamente, sua crítica ao federalismo e à oligarquização política, que o levará à centralização, tem influência no pensamento político de Alberto Torres. Esse argumento estava presente desde o início da sua produção intelectual, mais especificamente em Saneamento do Brasil (1918). Para tanto, Penna afirmava que a Constituição de 1891 e o federalismo eram alternativas cruéis, propondo como solução a revisão constitucional proposta por Torres. Em resumo, alertava: "A constituição que nos infelicita há 25 anos temporã, inadaptável, inexequível e inconveniente aos legítimos interesses do Brasil, e tem sido a causa máxima de todas as calamidades que vamos sucumbindo"'.

Por esse ponto de vista, a questão do federalismo assumia duas frentes interligadas. Uma relacionada à Constituição de 1891 e as consequências negativas do federalismo para o país. Outra pautada nos prejuízos para um projeto de integração nacional e de saúde pública. Penna concluía, no âmbito moral, que o federalismo representava um processo de fragmentaçáo nacional e favorecia apenas a "politicalha", que por sua vez pretendia assegurar o domínio da via eleitoral do país:

E assim; o Brasil, dividido em 21 fazendas, tornou-se a grande propriedade de um sindicato politicalheiro. De quatro em quatro anos um feitor nomeado pelo antecessor, com o simulacro de escolha livre pelos servos da gleba, superintende com poderes absolutos os interesses do sindicato e indica os capatazes das fazendas, pessoas de sua inteira confiança, mantidas enquanto servilmente obedientes ao seu despotismo e convenientemente escravizadores dos servos sob seu imediato domínio².

Portanto, do seu ponto de vista, a saúde pública e a política estavam integradas para alavancar o país àquele sentido de civilização que almejava. A retórica de cunho nacionalista e a idealização da "consciência sanitária" como solução para um Brasil desassistido, como observado no item anterior, facilitaram a sua escalada como homem público e o aumento da sua rede de sociabilidade na burocracia governamental (cf.: GOMES; HANSEN, 2016).

Hochman (2012, p. 79) resume essa perspectiva da seguinte forma: "Consciência sanitária + mudanças políticas e constitucionais = política nacional de saúde pública”. Essa foi a equação do pensamento de Penna para exigir um intervencionismo e maior centralização política. O resultado dessa fórmula emanciparia o brasileiro para uma identidade própria e consciente da sua responsabilidade higiênica, moral e política. Como fazia recorrentemente, Penna avaliava que a questão moral da classe política prejudicava a execução dos projetos

\footnotetext{
${ }^{1}$ PENNA, Belisário. Saneamento do Brasil. Rio de Janeiro, Revista dos Tribunaes, p. 63, 1918.

2 PENNA, Belisário. O grande mal. [s.d., s.l.] (recorte avulso, Fundo Belisário Penna, DAD-COC).
} 
salvacionistas. Para ele, o novo regime foi construído por uma "politicalha prostituidora da República". Insistia que a "consciência sanitária" resolveria problemas físicos e de ordem moral, na medida em que atuasse tanto nas classes subalternas quanto nas direçóes políticas. Era o que nomeava de saneamento cívico ${ }^{4}$. Evidentemente, enquanto homem público e portador da consciência nacional, Penna acreditava estar imune aos interesses dos grupos políticos que criticava. Sua equação de salvação nacional consistia em: consciência sanitária + nacionalismo + centralização $=$ organicidade nacional .

Ao situar Penna ao lado dos dissidentes, representado por Vargas no episódio que ficou conhecido como "Revolução de 1930", não significa que ignoro a presença de outros agentes nesse processo histórico. Aliás, esse ponto ajuda a compreender a miscelânea de grupos envolvidos em seu desfecho mencionados por Pandolfi e Grynszpan (2003). Essa também é uma característica do argumento de Edgard De Decca (2004, p. 81-87) ao explicar a presença dos blocos operário e camponês que tiveram sua participação ofuscada pela ala considerada vencedora. Ao contrapor a memória histórica do golpe de 1930, o autor salienta que o fato de diferentes grupos elegerem as oligarquias dominantes como inimigo em comum não pressupóe que compartilhavam as mesmas propostas políticas de ação e ideologia. Essa memória histórica voltada à análise da derrocada das oligarquias dominantes ocultou a luta de classes e, por exemplo, a ascensão de outro movimento que se tornaria inimigo dos vencedores: o comunismo (DE DECCA, 2004, p. 105).

De fato, a vitória de Júlio Prestes representou um aprofundamento na crise das oligarquias que Penna criticava há mais de uma década. A derrota de Vargas nas urnas não diminuiu o ímpeto da burguesia dissidente, de grupos operários e do tenentismo. Contudo, se antes das eleiçóes as articulaçóes em torno de um movimento golpista eram desencontradas, após o pleito havia um maior apelo por essa alternativa. $\mathrm{O}$ apoio do ex-presidente do Rio Grande do Sul, Borges de Medeiros (1863-1961), e do militar Góis Monteiro (1889-1956), fortaleceu as tratativas de tomada de poder pela via golpista (CARONE, 1974, p. 425). Finalmente, no início de outubro as ações foram desencadeadas resultando no final daquele mês na queda de Washington Luís e na conduçáo provisória de Getúlio Vargas à presidência.

A tomada de poder em 1930 pode ser compreendida, entre outras razóes, como a urgência em refazer o pacto oligárquico frente às disputas de poder e os novos conceitos de sociedade, como por exemplo, industrialismo e autoritarismo. São posições que desafiavam a lógica agroexportadora nacional e a mudança de orientação na política econômica, particularmente em relação à modernização do Estado e no tratamento de questóes sociais sob a tutela do poder público. Assim sendo, a lógica de um laissez-faire à brasileira era substi-

\footnotetext{
${ }^{3}$ Expressão utilizada por Belisário Penna em: PENNA, Belisário. As forças armadas e o povo. Porto Alegre, out. 1930, p. 5. (recorte avulso, Fundo Belisário Penna, DAD-COC).

${ }^{4}$ PENNA, Belisário. Politica de vermes. Conferência realizada em Sáo Paulo, a convite do Partido da Mocidade, 21 out. 1926, p. 16.
} 
tuída pela presença de um Estado regulador. A conjuntura desse período impunha um novo tratamento com a produção e com o trabalhador. Para o funcionamento do mercado à luz daquele contexto, o Estado deveria incorporar não somente a massa trabalhadora, como reorientar e regular as condições de trabalho. Esse ponto gerou uma série de reformas trabalhistas durante a Era Vargas, fruto de negociações políticas advindas das pressões de uma classe social em expansão.

Do mesmo modo é preciso entender que esse episódio não significou apenas rupturas. Como menciona Viscardi (2019, p. 256), o Estado varguista se caracterizou pela continuação de projetos vinculados ao passado oligárquico. Além disso, a centralização e intervenção na saúde são exemplos marcantes e agregadores de diferentes propostas de nação nascidas na Primeira República, como apontou Hochman (2012). A centralização, para Penna, indicava a regulação do Estado na vida social e beneficiaria seus projetos no campo da saúde pública.

Igualmente é oportuno sublinhar que a Aliança Liberal não representou a adesão homogênea do que podemos classificar como classe intelectual. Adeptos do pensamento autoritário como Plínio Salgado (1895-1975), Oliveira Vianna (1883-1951) e Alceu Amoroso Lima (1893-1983) não estavam ligados à Aliança e à tomada de poder. Outros como Cassiano Ricardo (1895-1974), Menotti del Picchia (1892-1988) e até mesmo Azevedo Amaral (18811942) foram partidários de Júlio Prestes (OLIVEIRA, 1980, p. 516). Isto não os impediu de intensa participação política na década seguinte.

Por sua vez, algumas demandas do Exército passaram a fazer parte da contraofensiva, o que motivava a participação de diferentes hierarquias militares. Entre elas havia a anistia aos revoltosos da década 1920 e a formação de um Estado conservador-autoritário. Juarez Távora (1898-1975), nesse caso, era um entusiasta da difusão da pequena propriedade e da organizaçáo nacional idealizada por Alberto Torres. Enquanto uma parcela tenentista seguia Prestes na aliança de classes subalternas, a posição majoritária representada por Távora era direcionada para a autonomia, neutralidade e racionalização de um Estado forte, em posição superior às classes (CAMARGO, 1983, p. 36). O apoio dos militares ao movimento armado, substanciado pelos civis aliancistas, acabou por marginalizar o setor liberal do movimento. Com a tomada de poder os militares conseguiriam paulatinamente adentrar na burocracia estatal.

Do ponto de vista de Penna, não há contradiçôes no diálogo entre a Aliança Liberal e os tenentes, que compartilhavam pautas em comum, como o voto secreto, o distanciamento do liberalismo e a questão social. Na verdade, essa união agradava Penna porque entre as exigências dos militares estava inclusa a moralização política. Segundo ele, era preciso congregar os militares com os irmãos civis 5 . Seu apoio sinalizava o elo entre oligarquias dissidentes e a classe militar, uma uniáo que tornava a tomada de poder possível. Para evitar

\footnotetext{
${ }_{5}^{5}$ PENNA, Belisário. As forças armadas e o povo. Porto Alegre, out. 1930 (recorte avulso, Fundo Belisário Penna, DAD-COC), p. 3.
} 
Por uma “ConsciênCia SANitária” reVolucionária: a participaÇấo do médico Belisário Penna em outubro DE I930

Leonardo Dallacqua de Carvalho

confusóes interpretativas é preciso tratar com mais vagar a aproximação de Penna com o discurso tenentista.

A eclosão da Revolta de 1924 tornou manifesto o seu desprezo ao presidente Artur Bernardes e ao estado de sítio instaurado, posicionando-se favorável ao ato dos militares liderados pelo General Isidoro Dias Lopes (1865-1949). O episódio de 1924 pode ser definido como uma continuação mais organizada da rebeliáo tenentista de 1922, marcada pela Marcha dos Dezoito do Forte. Ainda que tenha sido fracassado e reprimido pelas forças federais, o movimento tenentista de 1922 surge como uma voz esperançosa frente aos interesses de setores oligárquicos dominantes. No movimento iniciado em 5 de julho de 1924, militares tentaram tomar de assalto o governo de Bernardes e deflagraram uma série de combates na capital e no oeste do Estado de Sáo Paulo.

O documento que melhor exprime a ótica de Penna sobre a Revolta de 1924 foi um manifesto publicado em 25 de julho de 1924 intitulado "À minha mulher e meus filhos". O texto segue a linha das denúncias pronunciadas nos anos anteriores contra o coronelismo, o vício dos cargos públicos, as fraudes eleitorais, a queda da moralidade nacional, a falta de responsabilidade com a população e a higiene. Em tom mais grave, considerava a presidência de Artur Bernardes responsável por violência e espionagem. Ao avaliar a gestão Bernardes como decisiva para a instauração de um caos nacional, Penna ressaltava que uma revolução constituiria a única alternativa para a mudança de atitude em benefício do país. Logo de início justificou a sua posição favorável aos militares por considerar uma preocupação patriótica, sem interesses escusos, como a instauração de uma ditadura militar, da qual era contrário desde os tempos de Hermes da Fonseca (1855-1923). Ao ler o manifesto emitido pelos revoltosos, contudo, justificava que: “[...] abracei a revolução, cujos princípios são os mesmos pelos quais me bato sem tréguas e sem temor, pela palavra escrita e falada, desde 1916”6.

Esse parece ser o ponto-chave para compreender a adesão de Penna ao tenentismo, pois mesmo a organização revolucionária pertencendo aos quartéis, as pautas convergiam com o seu projeto de naçáo. Os tenentes defendiam uma moralização política contra as oligarquias cafeeiras, um tema que custava caro a Penna. Portanto, entendia o movimento menos em sua conotação militar, e mais como indivíduos instrumentalizados para liderar uma revolução nacional.

O discurso de Penna sobre os militares tem certa complexidade. Até 1924, sua posição havia sido de resistência em relação aos setores militares na administração pública. Quando tratou da participaçáo dos militares no golpe de 1889, entendeu que o grupo foi ludibriado por ideólogos e demagogos da causa republicana. Em certo sentido, a intenção era relativizar a participaçáo dos militares em 1889 e sugerir que, assim como ele, o apoio ao republicanismo era eivado de "bons intuitos". Todavia, no decorrer da década de 1920, a partir do

${ }^{6}$ PENNA, Belisário. À minha mulher e meus filhos. [s.l.] 25 jul. 1924 (recorte avulso, Fundo Belisário Penna, DAD-COC), p. 5. 


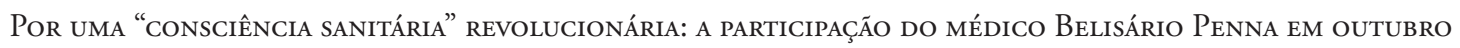
DE I930

Leonardo Dallacqua de Carvalho

momento que se aproxima do tenentismo, há um reposicionamento quanto à participação militar na vida pública, histórica e política do país. Em sua justificativa, alguns anos mais tarde, menciona:

Creio firmemente na confraternização dos militares com os irmãos civis. Esta crença provém da convivência com dezenas de oficiais desde 1919, quando dirigi um posto de profilaxia na Villa Militar, mais tarde na prisão, por haver justificado e aplaudido, em publicação na imprensa, a revolução de 24 . Eu, que antes desses contatos, não nutria a simpatia pela farda; que a julgava contaminada pelos vermes da politicalha, com a mentalidade atrasada de que a sua função era a de obediência passiva às ordens do governo, sem outro ideal que o crescente aumento do soldo, promoçóes rápidas e reformas vantajosas, deparei com numerosos oficiais de grande cultura, não só militar como geral, a par e interessados pelos problemas nacionais, convencidos da premente necessidade de sairmos disso, para que se pratique realmente o regime republicano proclamado pelo Exército?.

A aproximação entre militares e civis sugere que, para Penna, somente os setores das forças armadas poderiam viabilizar um projeto de um Estado autoritário, centralizado, nacionalista e reformista. Penna buscou uma raiz comum em 1919 para justificar que seu pensamento em relação aos militares havia mudado. Mas em que medida seu discurso foi alterado? Para começar, a perspectiva da Proclamação da República pelos militares foi vista como um ato benevolente, uma vez que a ação foi realizada em nome do povo. Embora reconheça que o governo de D. Pedro II fosse legal, caracterizou o movimento dos militares como portador do objetivo de fundar um governo de soberania popular. Entre os nomes, destaca "o bravo general Deodoro da Fonseca" e o "impoluto Benjamin Constant"8 (PENNA, 1930, p. 2-3). Pela perspectiva de um Penna envolvido com o tenentismo, os militares passaram a exercer um papel fundamental para salvar a nação da política oligárquica. Para que a narrativa vingasse, portanto, era preciso desvinculá-los de qualquer mácula ligada à fundação da República. Em vista dessa reinterpretação, os militares foram classificados como um grupo que foi iludido pelos ideólogos do republicanismo para a tomada de poder. Nesse sentido, Deodoro da Fonseca (1827-1892) e o positivista Benjamin Constant (1836-1891) tornam-se símbolos nacionais em seu discurso.

$\mathrm{O}$ apoio público aos tenentes era em direção a nomes como o do General Isidoro Dias Lopes e Juarez Távora. A crítica jurídico-política às oligarquias, a defesa da centralização e o discurso de salvação e regeneração nacional justificam a aproximação entre Penna e esses militares. Távora caracterizava-se por ser um antiliberal e propositor de uma revisão constitucional. Igualmente, a função dos militares na sociedade deveria responder à emancipação

\footnotetext{
${ }^{7}$ PENNA, Belisário. As forças armadas e o povo. op. cit., p. 4.

${ }^{8}$ Ibidem, p. 2-3. 


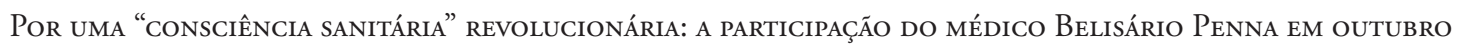
DE I930

Leonardo Dallacqua de Carvalho

das classes populares ainda desprovidas de força para derrubar a oligarquia dominante. Segundo a visão de Penna:

Do Exército partiram os primeiros movimentos de repulsa e de revolta contra os fraudadores do regime. A epopeia de Copacabana, em 22, a revolução militar de 5 de julho de 24, seguida da épica trajetória de um punhado de valorosos oficiais através do território pátrio levantaram o ânimo do povo e criaram o espírito de revolução, que avassalou todo o país na certeza de que os irmãos de posse das armas virão em seu auxílio para lavar a honra da nação e libertá-la da prepotência, do arbítrio e da traficância de um ajuntamento oligárquico sem patriotismo, sem fé, nem lei'.

Penna pertencia à fração que acreditava no sentimento patriótico do Exército para justificar uma ação revoltosa para reestabelecer a ordem. As mobilizaçóes de 1922 e 1924 eram entendidas por ele como uma reação ao status quo político. Militares e povo formariam uma frente única capaz de derrubar o que chamou de "bastilha da corrupçấo"10. Essa parece ter sido a imagem político-social construída para justificar sua adesão ao golpe de 1930. Ao compartilhar da visão tenentista de reformismo e luta contra as oligarquias, esperava que em algum momento as forças armadas e uma parcela da população, mesmo que elitizada, somariam forças.

A questão partidária também ajuda a explicar o envolvimento de Penna com os aliancistas. A partir de meados de 1920 fez oposição à classe política dominante por meio da movimentação partidária, endossando as fileiras do Partido da Mocidade e do Partido Democrático. A começar por uma perspectiva político-legalista e conservadora, entendia que algumas medidas, como o voto secreto, mudariam a estrutura fraudulenta das eleições. Sua presença nos partidos de caráter oposicionista foi um fator para costurar relaçóes com o projeto aliancista. Não à toa o próprio Partido Democrático apoiou a candidatura à presidência de Getúlio Vargas, simpatizou com o movimento revolucionário e postou-se como um adversário ferrenho a Washington Luís. Penna dialogava com o grupo oligárquico em cisão com a classe política dominante.

Como referido no início do texto, o ponto temporal de aproximação deu-se quando foi solicitado para estudar as condiçóes sanitárias do Rio Grande do Sul, em 1929. Naquele momento Penna se aproximou de Oswaldo Aranha (1894-1960) e Getúlio Vargas. No que diz respeito a Vargas, passou a considerá-lo um político capaz de resolver os problemas nacionais e um possível executor do seu projeto de nação, dando-lhe a autonomia que tanto almejava. No Rio Grande do Sul encontrou um grupo político que partilhava de parte de suas convicçôes, principalmente de caráter agrarista. A política rio-grandense não deve ser classificada

\footnotetext{
${ }_{9}^{9}$ Ibidem, p. 3.

${ }^{10}$ Ibidem, p. 5.

Topoi (Rio J.), Rio de Janeiro, v. 22, n. 48, p. 875-896, set./dez. 2021 | www.revistatopoi.org
} 
naquele momento como exclusivamente industrial, uma vez que a identificação com o meio rural era uma característica de facçóes políticas apoiadoras da Aliança Liberal (FAUSTO, 1997, p. 60). ${ }^{11}$ De modo que não há contrassenso entre uma perspectiva de "rumo ao campo" defendida por Penna e outra "rumo à urbanizaçáo", tese reducionista que por vezes classificou o golpe de 1930 como um conflito entre oligarquia rural e burguesia industrial. Não pretendo insinuar que náo havia um peso nessa disputa, mas é preciso expandir as demais perspectivas para compreender o desfecho do golpe de 1930 e a participação de Penna.

O movimento armado em outubro resultou, no final daquele mês, na designação de Getúlio Vargas como presidente do Governo Provisório. Com a montagem do novo governo, Penna foi empossado em novembro no cargo de Diretor do Departamento Nacional de Saúde Pública.

Periódicos como o jornal carioca Diário da Noite, assim como O Jornal do Brasil, enalteciam uma revolução que chegava para alterar o status quo. Em 30 de outubro, o periódico trazia a seguinte mensagem: "Um grande programa, cheio de ideal, elaborado nos dias amargos de exílio foi hoje exposto aos profissionais da imprensa pelo grande vencedor"12. Havia em uma parcela da populaçáo a crença de que era inaugurado um novo tempo político para o país.

O Jornal do Brasil interpretava o movimento como uma "Revolução Triunfante" e buscava em suas lideranças a idealização de mudanças nos rumos políticos. No dia 30 de outubro de 1930, um repórter do Jornal do Brasil encontrou-se com Oswaldo Aranha e narrou: "O chefe gaúcho é um admirável tipo de homem. Alto, forte, revela uma notável força física. Os seus cabelos louros, onde já aparecem uns fios alvíssimos, coroam uma fronte larga e inteligente"13. Quando questionado sobre os objetivos da revolução, disse Oswaldo Aranha:

Já tenho afirmado que este movimento não é feito por homens nem contra homens. É feito pelo povo e para a República Brasileira. A consciência do nosso país se afirmou agora de uma forma definitiva, não há como a de um vasto e imenso território, povoado por uma raça dispersa, desinteressada, sem sentimentos de unidade e de fraternidade, sem idealidade comum, sem o espírito de fraternidade e de congraçamento, e afinal, completamente desprovida de uma superior educação cívica ${ }^{14}$.

O discurso de Oswaldo Aranha ao Jornal do Brasil facilita entender o porquê Penna se aproximou do movimento. Integração territorial e de uma raça dispersa, espírito de frater-

\footnotetext{
${ }^{11}$ Segundo este autor, os manifestos da Aliança Liberal não trazem um programa industrialista. A preocupaçáo com a indústria siderúrgica, por exemplo, não pode caracterizar uma perspectiva industrializante, uma vez que ela também era encontrada na plataforma política de Júlio Prestes (FAUSTO, 1997, p. 62-63).

${ }^{12}$ Diário da Noite. A revolução triunfante. Rio de Janeiro, ano II, n. 333, 30 out. 1930, p. 1.

${ }^{13}$ Jornal do Brasil. As grandes figuras do momento. Rio de Janeiro, ano XL, n. 256, 30 out. 1930, p. 6.

${ }^{14}$ Idem.
} 


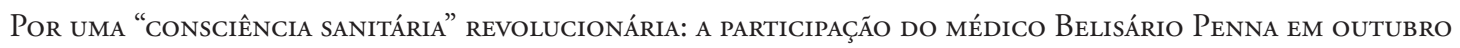
DE I930

Leonardo Dallacqua de Carvalho

nidade e sentimento de unidade são elementos que marcaram a leitura de nação de Penna. Uma revoluçáo seria o ponto de partida para um novo projeto de nação pautado na "consciência sanitária" anunciado ainda em Saneamento do Brasil.

Nas cartas endereçadas a Penna verifica-se narrativa semelhante. Os conteúdos eram uma mistura de congratulaçóes pelo desfecho do movimento e o reconhecimento da participação de Penna durante o processo. Do amigo Carlos Machado, de Juiz de Fora, recebeu a seguinte mensagem:

$[\ldots]$

Viva a Revolução Triunfante!

Viva a Aliança Liberal, mãe histórica e intrépida dessa empolgante Revolução, que veio provar inquestionavelmente ao mundo estrangeiro, que o Brasil em 21 dias mobiliza um formidável exército de forças, fazendo nesse lapso de tempo uma Revolução vitoriosa consciente da sua inteligência, da sua tática e do seu grande poder! Viva a nossa Liberdade oprimida por esse ignorantão sem sentimentos de moral, de dignidade e compostura com toda a sua corte de "Sóbas" obcecados na rapinagem da fortuna pública com o uso de processos merecedores da “cadeira elétrica”. Bandidos perigosos!! Não posso silenciar-me, vendo o amigo na direção do Departamento nacional de Saúde Pública.

[...] Deus conforte o seu espírito enchendo-o de luz e clarividência, vigorosa saúde e paz, para colaborar com Getúlio Vargas no levantamento desse Brasil invejável e cheio de possibilidades para todas as grandes conquistas ${ }^{15}$.

Os juristas Francisco Candido da Gama Junior e Roberto Lira (1902-1982) também encaminharam correspondências a Penna tratando sobre a tomada de poder e a sua indicação para diretor do DNSP. Francisco Junior mencionava que a indicação de Penna para a diretoria refletia nas intençóes da restauraçáo da vida republicana e da verdadeira democracia ${ }^{16}$. Por sua vez, Roberto Lira desejava "Que a Revolução distribua os Belisários Penna (e o Brasil tel-os-há muito?) pelos postos de responsabilidade na obra iniciada”. Semelhante a Oswaldo Aranha, Penna era imaginado como alguém que reestabeleceria uma nova ordem política ao Brasil. O médico Artur Neiva, seu amigo e companheiro de viagem do Instituto Oswaldo Cruz, parabenizava Penna por assumir as funçóes de diretor do DNSP em uma época de reconstrução nacional. Para Neiva, "O governo foi bem inspirado colocando-o à frente da Saúde Pública, onde atuará com eficiência, pois não lhe faltam tirocínio, competência e dedicação"17.

\footnotetext{
${ }^{15}$ MACHADO, Carlos V. A. [Correspondência]. Destinatário: Belisário Penna. Juiz de Fora, 12 nov. 1930, p. $1-2$.

${ }^{16}$ GAMA JUNIOR, Francisco Candido da. [Correspondência]. Destinatário: Belisário Penna. [s.l.] 18 nov. 1930; LIRA, Roberto. [Correspondência]. Destinatário: Belisário Penna. Rio de Janeiro, 13 nov. 1930

${ }^{17}$ NEIVA, Artur. [Correspondência]. Destinatário: Belisário Penna. São Paulo, 19 nov. 1930.
} 
Por uma “ConsciênCia SANitária” reVolucionária: a participaÇấo do médico Belisário Penna em outubro DE 1930

Leonardo Dallacqua de Carvalho

O mérito de Penna à frente da Saúde Pública também era reconhecido por periódicos. O Correio da Manhã, em 31 de outubro de 1930, salientava que o movimento teve Penna como uma de suas figuras mais expressivas, "[...] pela sinceridade de seus conceitos, pelo ardor de sua convicção" ${ }^{18}$. O paulista $A$ Gazeta considerava Penna uma glória nacional, uma vez que dedicou toda a sua vida pelo saneamento moral e material da nação ${ }^{19}$. Em 21 de novembro de 1930, para o mesmo jornal, Penna relatava o seu comprometimento com a Revolução e o DNSP. Quando questionado sobre o programa a ser executado na saúde pública em sua gestáo, ratificava por meio de um discurso nacionalista e dizia que o modelo estava comprometido com os preceitos da Revoluçáo. Complementava: "A Revolução não foi feita para perdoar, mas para punir e organizar" 20 .

Nesse sentido, o golpe de 1930 representou um marco no que diz respeito às ideias sendo transformadas em ações políticas. Influenciado por uma geração defensora de um Estado centralizador, o governo varguista buscou construir sua concepçáo de Estado passando pela institucionalização da saúde pública. Com a burocratização do pós-30 diversos intelectuais fizeram parte do aparato do Estado juntamente com seus projetos de nação que dialogaram, direta ou indiretamente, com a nova concepção de construção do Estado. Para Angela de Castro Gomes (1980, p. 29), o binômio centralizaçáo versus federalismo era o ponto de partida que agregava outras questốes políticas do país. Como se observou depois, um dos elementos principais da campanha Constituinte pretendia reestruturar esse sistema.

A rigor, uma série de propostas políticas começou a disputar espaço na tentativa de viabilizar a nação imaginada. As ideias não atuavam de forma isolada, mas orientando ações, agindo em situaçôes estratégicas, diretivas e prospectivas (FONSECA, 2007, p. 69).

Como tenho insistido, torna-se perigoso classificar a passagem da Primeira República para o Governo Vargas sinalizando apenas as rupturas. Ao revisitar esse período, Cláudia Viscardi e Cristina Fonseca apontam que tanto no âmbito da política quanto no da saúde pública havia continuidade em diversos projetos ideológicos que foram incorporados e reelaborados no governo varguista. Ao acompanhar o processo de burocratizaçáo do Estado e a criação do Ministério da Educação e Saúde Pública, Fonseca assevera que não houve ruptura com o que vinha sendo realizado anteriormente na saúde pública, mas uma incorporação das suas instituiçốes e dos seus agentes segundo o novo processo de State Building (FONSECA, 2007, p. 29).

Partindo do sociólogo Alberto Guerreiro Ramos (1915-1982) em estudo sobre a inteligência brasileira na década de 1930, Fonseca destaca que o grupo denominado por Ramos como "pragmático-crítico" contribuiu para a formação do quadro ideológico do novo governo. Esse grupo era composto por Gustavo Capanema (1900-1985), Francisco Campos

${ }^{18}$ Correio da Manhã. Um homem de fé: Belisário Penna chega hoje ao Rio. Rio de Janeiro, ano XXX, n. 11.001, 31 out. 1930, p. 2.

${ }^{19}$ A Gazeta. O ministério da instrução. São Paulo, ano XXV, n. 7435, 20 nov. 1930, p. 7.

${ }^{20}$ A Gazeta. O homem no seu lugar. São Paulo, ano XXV, n. 7436, 21 nov. 1930, p. 6. 
(1891-1968), Lindolfo Collor (1890-1942), Oliveira Vianna, Azevedo Amaral (1881-1942), entre outros. Tais intelectuais tinham uma "identificação com o elemento nacional" e uma "sensibilidade às condições contextuais típicas do meio em que vivem" (FONSECA, 2007, p. 65). Como lembra José Beired, diferentes intelectuais nesse período buscaram assumir a tarefa de orientar o destino do Brasil. Embora houvesse a influência de leituras estrangeiras, não se tratava de puro mimetismo de ideias, mas de produção de reflexôes originais, interpretaçôes e discussão de problemas relacionados à agenda brasileira (BEIRED, 2007, p. 153). Enquadro Penna nesse grupo, uma vez que a criaçáo de uma consciência nacional - especialmente uma "consciência sanitária" - era parte do seu projeto político.

Para Penna era antiga a ideia de que a descentralização e o federalismo prejudicavam o projeto de universalidade da saúde pública e da unidade nacional. Desse modo, à medida que a população havia sido abandonada e mergulhava na ignorância, a retomada para a regeneração ocorreria a partir de um Estado tutelar. Penna adotava a orientação de Alberto Torres, na qual pensava o governo centralizado como uma fortaleza para cumprir seu papel de agente desenvolvedor dos indivíduos e coordenador da sociedade:

Ao Estado cumpre igualar as possibilidades e os meios de trabalho e de propriedade. Só depois desta obra de regeneração de instituiçôes, costumes, tradiçôes e tendências, contrários ao desenvolvimento espontâneo de todas as capacidades pessoais e favoráveis à formação de relaçôes desiguais, se poderá decidir se o individualismo exprime um ideal, nas relaçóes do homem com a sociedade ${ }^{21}$ (TORRES, 1914, p. 158).

Para alterar a realidade era preciso confiar em um Estado tutelar que, por sua vez, estabelecesse os cuidados com a saúde pública e firmasse um compromisso com a reforma moral dos indivíduos. O Estado autoritário desejado por Penna, além da centralização política e administrativa, regularia e economia e controlaria a sociedade em vista de uma ordem social, principalmente no campo da saúde pública.

Participante do movimento de 1930, com um governo alinhado às suas perspectivas de nação, Penna recebeu ainda nas primeiras semanas de novembro a diretoria do Departamento Nacional de Saúde Pública. O cargo permitiu assumir antigos compromissos de sua agenda de saneamento. Com o apoio de um regime declaradamente centralizador e interventor, era mais uma chance de implementar as convicçóes que nortearam sua campanha sanitarista. Temas como lepra e alcoolismo voltaram a fazer parte das suas açóes verticais como homem público frente à diretoria. O novo modelo de Estado nacional modificou a antiga estrutura dos postos de profilaxia rural em diversos locais do país, ampliando e diversificando a ação do poder público (FONSECA, 2007, p. 51). Era a marca do fortalecimento do poder central como estratégia de unificar a nação.

${ }^{21}$ TORRES, Alberto. A organização nacional. Rio de Janeiro: Imprensa Nacional, 1914. 
Resumidamente, a partir de outubro de 1930, Penna participou da recém-criada estrutura do governo varguista, chegando a ocupar por três meses - substituindo Francisco Campos que retornaria à cadeira logo em seguida - o cargo de ministro interino do MESP, em 1931. Seu retorno à diretoria do DNSP foi breve. Uma série de atritos por falta de investimento e autonomia para gerir o departamento o colocou em rota de colisão com o governo, mais especificamente com o novo ministro do MESP, Washington Ferreira Pires (1892-1970), indicado por Olegário Maciel (1885-1933). Insinuou, inclusive, em entrevista ao periódico Jornal do Brasil ${ }^{22}$, que nenhum outro governo, mesmo os mais discricionários, restringiram a atuação do DNSP. Em 1932, abandonou o cargo e se distanciou provisoriamente da cena pública. Retornou aos holofotes públicos no final de 1935 como militante na Ação Integralista Brasileira (CARVALHO, 2019).

\section{Considerações finais}

O presente artigo demonstrou como ocorreu a participação de Belisário Penna no Golpe de 1930 e quais ideias mobilizaram suas açóes no curso do movimento. Para tanto, tratei da sua trajetória como médico e homem público e o seu pensamento político. A relação entre a história política e a história da saúde pública permite sublinhar o "[...] engajamento político e intelectual de médicos que pensaram sobre os dilemas do Brasil e dos brasileiros a partir dos temas da medicina, da doença e da saúde" (LIMA; HOCHMAN, 2015, p. XXII). Do ponto de vista de Penna, essa leitura de país baseada na tradição científica que adotava foi fundamental para os caminhos que trilhou dentro da administração pública. Evidentemente, nada disso ocorreu sem negociaçóes.

Náo à toa, busquei estabelecer ligaçóes com a sua produção intelectual e a de outros movimentos que ajudaram a construir o seu ideal de naçáo, como foi o caso do tenentismo. A "consciência sanitária", um conceito de recuperaçáo do país a partir do saneamento, o fez acreditar que seria possível aplicá-lo por meio de um projeto amplo, autoritário e centralizado administrativamente e politicamente, proposto por Vargas e seus apoiadores. Um projeto cujas características idealizava há anos em produçóes intelectuais como Saneamento do Brasil.

Se Penna atribuía à chamada revolução uma nova organização política nacional e a concretização imediata de seu projeto de naçáo saneada, o resultado foi a decepção. Embora não seja o objetivo deste texto contextualizar a sua presença no governo varguista, é necessário dizer que os primeiros anos do Governo Provisório foram de intensas negociaçóes com a

\footnotetext{
${ }^{22}$ Jornal do Brasil. Defendendo a autonomia do D. N. da Saúde Pública: Seu diretor, Dr. Belisário Penna, solta o primeiro brado de alarme contra o atentado que parece estar sendo preparado. Rio de Janeiro, ano XXLII, n. 268, 10 nov. 1932, p. 6.
} 
antiga oligarquia e os novos setores empresariais. As facçóes regionais não deixaram de fazer exigências e tentar manter sua influência e dominância nos estados após a Revolução. Sua gestão no DNSP foi prejudicada pelas excessivas restriçôes orçamentárias e impedimentos por parte do Governo para iniciar um projeto centralizado de grande envergadura. Penna observava a aplicação do seu projeto de nação cada vez mais distante. No interior do Governo Provisório observou além da ascensão de Gustavo Capanema, Getúlio Vargas e Oswaldo Aranha, a incorporação e influência de atores políticos como Olegário Maciel e Artur Bernardes, agentes políticos que interferiam cada vez mais nas decisóes do novo governo. Assim, acordos políticos feitos antes da tomada de poder, como as divisôes ministeriais entre os estados, foram reavaliados. Esta breve síntese demonstra que a marginalização de parte da oligarquia paulista náo representou o fim das negociatas políticas, apenas reorientou novos e antigos atores no tabuleiro da política brasileira.

Para Penna, o outubro de 1930 marcou a esperança de autonomia administrativa e financeira para o seu projeto de "consciência sanitária". Defendia há anos uma ação integrada entre civis e militares para extirpar da administração pública aquilo que considerava a corrupção dos valores morais e políticos do Brasil. Embora tenha se decepcionado ainda no início do Governo Provisório, esteve ao lado dos aliancistas na articulação da tomada de poder. Conservou amizade com atores históricos importantes desse processo como Oswaldo Aranha e Getúlio Vargas. No caso de Vargas, o enxergava como um agente capaz de viabilizar suas ideias em torno da saúde pública, cultivadas há mais de uma década. Mesmo fora do governo, a "consciência sanitária" permaneceu na ordem do dia. Anos mais tarde, próximo aos 70 anos de idade, Penna voltaria a propô-la em uma outra iniciativa: o integralismo.

\section{Fontes documentais}

A Gazeta. O homem no seu lugar. São Paulo, ano XXV, n. 7436, 21 nov. 1930.

A Gazeta. O ministério da instrução. São Paulo, ano XXV, n. 7435, 20 nov. 1930.

Correio da Manhã. Um homem de fé: Belisário Penna chega hoje ao Rio. Rio de Janeiro, ano XXX, n. 11.001, 31 out. 1930.

Diário da Noite. A revolução triunfante. Rio de Janeiro, ano II, n. 333, 30 out. 1930.

GAMA JUNIOR, Francisco Candido da. [Correspondência]. Destinatário: Belisário Penna. [s.1.] 18 nov. 1930.

Jornal do Brasil. As grandes figuras do momento. Rio de Janeiro, ano XL, n. 256, 30 out. 1930. Jornal do Brasil. Defendendo a autonomia do D. N. da Saúde Pública: Seu diretor, Dr. Belisário Penna, solta o primeiro brado de alarme contra o atentado que parece estar sendo preparado. Rio de Janeiro, ano XXLII, n. 268, 10 nov. 1932. 


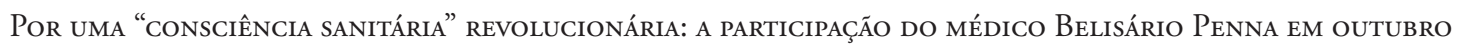
DE I930

Leonardo Dallacqua de Carvalho

LIRA, Roberto. [Correspondência]. Destinatário: Belisário Penna. Rio de Janeiro, 13 nov. 1930.

MACHADO, Carlos V. A. [Correspondência]. Destinatário: Belisário Penna. Juiz de Fora, 12 nov. 1930.

NEIVA, Artur. [Correspondência]. Destinatário: Belisário Penna. São Paulo, 19 nov. 1930.

PENNA, Belisário. À minha mulher e meus filhos. [s.l.] 25 jul 1924 (recorte avulso, Fundo Belisário Penna, DAD-COC).

PENNA, Belisário. As forças armadas e o povo. Porto Alegre, out. 1930 (recorte avulso, Fundo Belisário Penna, DAD-COC).

PENNA, Belisário. O grande mal. [s.d., s.l.] (recorte avulso, Fundo Belisário Penna, DADCOC).

PENNA, Belisário. Política de vermes. Conferência realizada em São Paulo, a convite do Partido da Mocidade, 21 out. 1926.

PENNA, Belisário. Saneamento do Brasil. Rio de Janeiro, Revista dos Tribunaes, 1918.

TORRES, Alberto. A organização nacional. Rio de Janeiro: Imprensa Nacional, 1914.

\section{Referências}

BEIRED, José Luís Bendicho. Os intelectuais e a direita autoritária no Brasil. Estudios Sociales, Santa Fé, v. 33, p. 123-154, 2007.

CAMARGO, Aspásia. A revolução das elites: conflitos regionais e centralização política. In: A Revolução de 30: Seminário Internacional. Brasília: Ed. da UnB, 1980.

CARONE, Edgard. A República Nova (1930-1937). São Paulo: Difusão Europeia do Livro, 1974.

CARONE, Edgard. A República Velha (evolução política). 2. ed. São Paulo: Difusão Europeia do Livro, 1974.

CARVALHO, Leonardo Dallacqua. O saneador do Brasil: saúde pública, política e integralismo na trajetória de Belisário Penna (1868-1939). Tese (Doutorado em História das Ciências e da Saúde). Rio de Janeiro: Fiocruz, 2019.

CASTRO SANTOS, Luiz Antonio de. O pensamento sanitarista na Primeira República: uma ideologia de construçáo da nacionalidade. Dados - Revista de Ciências Sociais, Rio de Janeiro, v. 28, p. 193-210, 1985.

DE DECCA, Edgar Salvadori. 1930, o silêncio dos vencidos: memória, história e revolução. São Paulo: Brasiliense, 2004. 


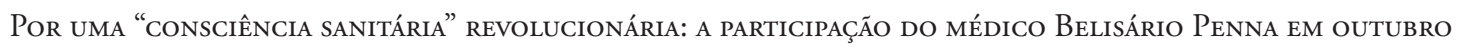
DE 1930

Leonardo Dallacqua de Carvalho

FAUSTO, Boris. A Revolução de 1930: historiografia e história. São Paulo: Companhia das Letras, 1997.

FAUSTO, Boris. A Revoluçáo de 1930. In: MOTA, Carlos Guilherme. Brasil em perspectiva. Rio de Janeiro: Editora Bertrand Brasil S.A., 1990.

FERREIRA, Marieta de Moraes; PINTO, Surama Conde Sá. A crise dos anos 1920 e a Revolução de 1930. In: FERREIRA, Jorge; DELGADO, Lucilia de Almeida Neves. O Brasil Republicano: o tempo do liberalismo excludente: da Proclamação da República à Revolução de 1930. v. 1. Rio de Janeiro: Civilização Brasileira, 2008.

FONSECA, Cristina Maria Oliveira. Saúde no Governo Vargas (1930-1945): dualidade institucional de um bem público. Rio de Janeiro: Editora Fiocruz, 2007.

GOMES, Angela de Castro; HANSEN, Patrícia Santos. Apresentação. Intelectuais, mediação cultural e projetos políticos: uma introdução para a delimitação do objeto de estudo. In: GOMES, Angela de Castro; HANSEN, Patrícia Santos (orgs.). Intelectuais mediadores: práticas culturais e ação política organização. Rio de Janeiro: Civilização Brasileira, 2016.

GOMES, Ângela de Castro (coord). Regionalismo e centralização política: partidos e Constituinte nos anos 30. Rio de Janeiro: Nova Fronteira, 1980.

HOCHMAN, Gilberto. A era do saneamento: as bases da política de saúde pública no Brasil. São Paulo: Hucitec, 2012.

HOCHMAN, Gilberto. Regulando os efeitos da interdependência: sobre as relaçóes entre saúde pública e construção do Estado (Brasil 1910-1930). Estudos Históricos, Rio de Janeiro, v. 6, n. 11, p. 40-61, 1993.

KROPF, Simone Petraglia. Doença de Chagas, doença do Brasil: ciência, saúde e nação, 19091962. Rio de Janeiro: Editora Fiocruz, 2009.

LEAL, Victor Nunes. Coronelismo, enxada e voto: o município e o regime representativo no Brasil. 2. ed. São Paulo: Alfa-Ômega, 1975.

LIMA, Nísia Trindade; HOCHMAN, Gilberto. Médicos intérpretes do Brasil: uma introdução. In: LIMA, Nísia Trindade; HOCHMAN, Gilberto (orgs.). Médicos intérpretes do Brasil. São Paulo: Hucitec, 2015.

LIMA, Nísia Trindade. Um sertão chamado Brasil: intelectuais e representação geográfica da identidade nacional. Rio de Janeiro: Revan: IUPERJ, UCAM, 1999.

MARTINS, Luciano. A Revolução de trinta e seu significado político. In: A Revolução de 30: Seminário Internacional. Brasília: Ed. da UnB, 1980.

OLIVEIRA, Lúcia Lippi. A questão nacional na Primeira República. 1. ed. Sáo Paulo: Brasiliense; Brasília: CNPq, 1990.

OLIVEIRA, Lúcia Lippi. As raízes da ordem: os intelectuais, a cultura e o Estado. In: $A$ Revolução de 30: Seminário Internacional. Brasília: Ed. da UnB, 1980. 
OLIVEIRA, Lucia Lippi. Revolução de 1930: uma bibliografia comentada. Revista Brasileira de Informação Bibliográfica em Ciências Sociais BIB, Rio de Janeiro, n. 4, p. 95-116, 1978. PANDOLFI, Dulce Chaves; GRYNSZPAN, Mário. Da Revolução de 30 ao golpe de 37: a depuração das elites. Revista de Sociologia e Política, n. 9, p. 7-23, 1997.

PANDOLFI, Dulce. Apresentação. In: PANDOLFI, Dulce (org.). Repensando o Estado Novo. Rio de Janeiro: Ed. Fundação Getúlio Vargas, 1999.

REIS, Elisa. Poder privado e construção do Estado sob a Primeira República. In: BOSCHI, Renato (org.). Corporativismo e desigualdade: a construçáo do espaço público no Brasil. Rio de Janeiro: IUPERJ/Rio Fundo Editora, 1991.

SANDES, Noé Freire. O passado como negócio. O tempo revolucionário (1930). Estudos Históricos, Rio de Janeiro, v. 43, p. 125-140, 2009.

SANTA ROSA, Virginio. O sentido do tenentismo. 3. ed. São Paulo: Alfa Ômega, 1976.

VISCARDI, Cláudia Maria Ribeiro. O teatro das oligarquias: uma revisão da "política do café com leite". Belo Horizonte, MG: Fino Traço, 2019. 